\title{
An Investigation into the Importance of Research and Development Activity in Health Sector Small and Medium-sized Companies in Wales
}

\author{
Brychan Thomas ${ }^{1 *}$, Lyndon Murphy ${ }^{2}$ and Christopher Miller ${ }^{3}$ \\ 1University of South Wales, Pontypridd, CF37 1DL, United Kingdom \\ ${ }^{2}$ Aberystwyth Business School, Aberystwyth University, \\ Penglais, Aberystwyth, SY23 3FL, United Kingdom \\ ${ }^{3}$ Cardiff School of Management, Cardiff Metropolitan University, \\ Llandaff Campus, Western Avenue, Cardiff, CF5 2YB, United Kingdom
}

E-mail: brychan.thomas@southwales.ac.uk; lym18@aber.ac.uk; cmiller@cardiffmet.ac.uk

*Corresponding author details: Professor Brychan Thomas; brychan.thomas@southwales.ac.uk

\begin{abstract}
Purpose - The aim of this paper is to investigate the importance of research and development activity in Health sector small and medium-sized companies in Wales.

Design/methodology/approach - The case study approach involved extensive examination of the phenomenon of research and development in the organisations researched. Data for the case studies has been obtained from information relating to the organisations investigated. These have been combined with secondary and internal data sources from the organisations for completeness. Three case studies have been undertaken in the health sector in Wales and these are reported according to the company background, research and development (R\&D) activity and the importance of R\&D.
\end{abstract}

Findings - The health companies studied reported that they undertook R\&D in partnership with other companies, universities and the NHS. In particular universities were considered to be important sources of knowledge and technological expertise. In fact, R\&D in universities has the important aim of providing postgraduate students with research skills, and related to this, public R\&D creates considerable knowledge spillovers to small health businesses through "tacit" knowledge, training of researchers and collaborative ventures.

Originality/value - A significant policy research question regarding the importance of R\&D activity for health sector small and medium-sized companies asks to what extent domestic technology progress is influenced by global developments or domestic R\&D. The answer appears to be that domestic technology progress is influenced by a combination of both global developments and domestic R\&D.

Keywords: health; R\&D; SMEs; policy; funding

\section{INTRODUCTION}

This paper considers Health sector small and mediumsized companies in Wales in terms of the importance of their R\&D activities, developments, policy and funding. Initially this is investigated from a general assessment of the Health business sector involving research collaborations and the commercialisation of ideas through partnerships between industry, Higher Education (HE) and the National Health Service (NHS).

In the Principality, the Wales Office of Research and Development for Health and Social Care (WORD) has the strategic aim to generate evidence to inform policy and practice in health and social care (Cooksey, 2006). The high-quality evidence provided is for the benefit of patients and the public. The health and social care priorities of the Welsh Government (WG) are reflected in the policy on R\&D and this is provided in their ten-year strategy "Designed for Life". There is direct accountability to the WG and to the Minister for Health and Social Services. The Advisory Board of WORD provides consultation and advice on the strategic direction of R\&D in health and social care, and key external and internal stakeholders 
ensure the effective deployment of services and an overall co-ordinated approach. A budget is provided for WORD to develop supporting infrastructure for clinical research ( $€ 4.4 \mathrm{~m} \mathrm{pa}$ ), Responsive Grants Scheme ( $£ 1 \mathrm{~m} \mathrm{pa}$ ), fellowship programme ( $£ 2 \mathrm{~m}$ pa for lectureships and fellowships) and national research initiatives $(£ 400 \mathrm{k}$ pa) The Wales Gene Park, Wales Cancer Bank and service costs of research are also supported ( $£ 15 \mathrm{~m}$ pa) (Cooksey, 2006). Researchers in Wales can also apply for funding to the Medical Research Council (MRC) and WORD through the Welsh arm of the Association of the British Pharmaceutical Industry (ABPI) ABPI have discussed investment from industry for research into cancer and informatics and have also explored the leverage of EU funds (Cooksey, 2006).

With regard to the commercialisation of science, in the area of health research, current examples of significant advances include improvements in the assessment of cardiovascular disease and foetal heart monitoring by the use of Huntleigh Diagnostic's Doppler ultrasound equipment, Cardiff University's work on human stem cell research, bioluminescence labelling technology and the latest brain scanning technologies associated with complementary applications for human based brain imaging (WAG, 2006, p. 19).

In this paper definitional aspects of the Health business sector are considered in terms of the classification of health R\&D performers followed by definitions of health $R \& D$. A case study approach is undertaken to explore the R\&D activities of three health sector companies. Following a summary/discussion of the findings in relation to government policies, conclusions are drawn with regard to the importance of R\&D for technological progress of health sector small companies.

\section{R\&D LITERATURE REVIEW}

\section{Background}

For this literature review, R\&D activities of companies are considered in terms of the protection of competitive advantage, intellectual property (IP), patents, imitation of inventions, impact of R\&D, internal and external R\&D, and R\&D studies which are relevant to the study of small and medium-sized health companies. To begin with Levin et al (1987), in a survey of large corporations in the United States examined a number of methods used by enterprises to protect the competitive advantage of new or improved processes (Miller et al, 2020) and products. These were patents, secrecy, lead time, moving quickly along the learning curve and sales and service. With "first mover advantage" it was found that secrecy was the most widely used method to protect intellectual property (IP) in industry (Arundel, 2001). Since small "outsider" enterprises in markets controlled by oligopolies will often need patents in order to release new products, they will often licence production to a larger firm (Mazzoleni and Nelson, 1998). Innovation surveys have found similar results, for example the survey reported by Phillips (1997). Also, in some sectors the functions of patents can be replaced by copyright (Revesz, 1999). Once knowledge is created and due to non-exclusion, it is difficult to stop others acquiring it and this is called the non-appropriation problem (Revesz and Boldeman, 2006). In relation to the non-appropriation problem Quah (2003) has considered the acquisition of knowledge with regard to the information society and the public good aspects. Further to this with knowledge there is the implication of only charging for marginal dissemination costs (Arrow, 1962). As a result, additional learning costs will be incurred by the user when making use of this knowledge (Mandeville, 1998). It could be suggested that since the market provides the means for appropriating innovation benefits, there will be no need for supplementation through government intervention in the form of IP protection and R\&D subsidies, since oligopoly market conditions will be apparent in R\&D intensive service industries and manufacturing (Mandeville et al, 1982).

Several surveys have been undertaken to consider the time delay and cost in the imitation of inventions (Revesz and Boldeman, 2006). For example, more than one hundred and twenty respondents to a survey (mostly United States R\&D executives) were asked by Levin et al (1987) for an estimation of time and costs needed to copy innovations by a competitor and it was found that in less than 5 years most inventions could be imitated. Similarly, Mansfield (1981; 1985) revealed that reverse engineering, personal contacts and the movement of staff between companies (Thomas and Murphy, 2019a; 2019b; 2020) were the principal sources of the leakages of information.

Regarding patents it is perceived that there are advantages in reducing patent monopolies by limiting protection or reducing duration (Scotchmer, 2004; Mazzoleni and Nelson; 1998 and Revesz, 1999). There can also be a reluctance to seek strong protection for patents (Scotchmer, 2004; Mandeville et al, 1982; Mazzoleni and Nelson, 1998). Before spillover benefits are known it is difficult to estimate these for R\&D projects (Allen Consulting, 2005). Michael Polanyi (1943) suggested the replacement of patent monopolies with the government control of invention licensing rights by an expert industry panel awarding the inventor.

\section{Research and Development Activity}

Generally, R\&D studies have only considered manufacturing (Thomas and Thomas, 2019), since it represents the largest spend on R\&D than any other sector (Revesz and Boldeman, 2006). The cost savings for 12 manufacturing sectors in the United States were estimated by Nadiri and Theofanis (1994) - the social manufacturing rate of return on public R\&D was found to be between six and nine per cent, by adding the marginal cost savings estimates. The rate at which companies registered significant product innovations and patents across technology fields in the United States was analysed by Acs et al (1994) who found that own R\&D activity was important for large businesses who ran their own laboratories whereas smaller businesses benefited from publicly funded research knowledge (effectiveness of public research appeared to be enhanced by universities near to private sector research laboratories). Similar results were found by Audretsch and Vivarelli (1996) when investigating patenting activity for 15 Italian regions (own R\&D was important for large businesses and regional university scientific research activity) (Thomas, 2019). The productivity growth rate in eighteen United States manufacturing sectors between 1953 and 1983 was related to the rate of publication of scientific papers for 9 scientific fields by Adams (1990) (productivity growth was found to be dependent on accumulated field specific scientific research and on industry employment in appropriate fields for scientists). The relationship between the size of R\&D activity and the science base for 14 United States R\&D sectors, between 1961 and 1986, was examined by Adams (1993). He found that the size of the scientific base had a significant positive impact on $R \& D$ activity levels. R\&D in universities has the important aim to provide post graduate students with research skills, and related to this public $\mathrm{R} \& \mathrm{D}$ impulse considerable knowledge spillovers to business through "tacit" knowledge, training of researchers, collaborative ventures, resolving technological dilemmas and scientific and new discoveries (Revesz and Boldeman, 2006). 
The Importance and Impact of Research and Development With the impact of $R \& D$, simple cost reduction measurement was followed by early research into the impact of R\&D on productivity (Revesz and Boldeman, 2006). A pioneering study was undertaken by Grilliches (1957) involving a cost benefit analysis of the development of hybrid corn varieties in United States government research stations. Case studies undertaken on cost reductions from R\&D in certain areas have provided interesting results (Revesz and Boldeman, 2006). Bresnahan (1986) considered consumer surplus through cost reducations in financial services arising from mainframe computers between 1958 and 1972 in the United States. Trajtenberg (1990), in a case study of computerised tomography scanners, found the rate of return to $R \& D$ in the United States to be $270 \%$ a year. The rate of return to business R\&D was examined by Mansfield et al (1977) using several case studies in the United States. Unfortunately, a major drawback of case studies is that they only consider innovations that are successful (Revesz and Boldeman, 2006). Alternatively, case studies can be useful when information about R\&D costs and outcomes, which are commercially sensitive, is available from private businesses (Thomas et al, 2020).

An estimation of knowledge spillovers was considered to be the main challenge for economic analysis of R\&D by Grilliches (1992). A number of measures have been propounded for technology knowledge flows. These include the proximity in industrial or research field classification, statistics on foreign direct investment (FDI), statistics on licence fees and royalties, data on foreign trade, input and output linkages across sectors, citations on patents and patent registrations (Eaton and Kortum, 1996, 1999; Mohnen, 1996; Grilliches, 1992). According to Jaffe and Trajtenberg (1998) and Jaffe et al (1993) patent citations appear to be the best approach to determine knowledge flows between industries, regions and countries. Internal R\&D can be measured by country (macro), sector (meso) or firm (micro) and external R\&D similarly (external R\&D indicators can be determined by R\&D stocks or external sources and weighted by knowledge flow indicators - patent statistics, for example) (Revesz and Boldeman, 2006). Grilliches (1992) argued that the rate of depreciation of knowledge is quicker at the micro level than at the macro level. Statistical evidence on the obsolescence of R\&D capital at the micro level in a technology competitive and dynamic environment supports the depreciation of knowledge supported by Schumpeter's (1934; 1942) creative destruction (Caballero and Jaffe, 1993).

From the findings of the literature review a significant policy research question for the importance of $R \& D$ activity for health sector small and medium-sized companies, is to what extent domestic technology progress is influenced by global developments or domestic R\&D. This study therefore investigates this research question in terms of the health business sector in Wales.

\section{HEALTH BUSINESS SECTOR}

Some complex challenges will need to be met if effective mechanisms are to be developed between the health business sector, innovators, the National Health Service (NHS) and individuals. In relation to this, four key themes were identified in a review of bioscience (Ernst Young, 2003) and these were building the science base, innovation and commercialisation, critical mass and unified leadership. This is appropriate to the research spectrum involving basic research through to translational research. Two hundred and ninety companies active in bioscience were identified in the review and these included drug discovery technologies and systems, noninvasive surgery, diagnostics (in vivo and in vitro), medical devices, clinical trials and pharmaceuticals. It recognised that there is a need for research collaborations which are multidisciplinary when appropriate, and for there to be active partnerships between industry, academia and the NHS. This is highlighted by clinical research where to meet the needs of industry it is necessary to move towards a single system that delivers quality and rapid access at reasonable costs (McKinsey, 2005). In order to build collaborations in bioscience, industry networks have been established. There are also the NHS networks provided by health professional advisory committees. It is believed that these could work together to determine potential clinical collaborations within the NHS, to provide access points for industry. For the commercialisation of ideas, partnerships between industry, HE and the NHS can generate income of benefit to research through reinvestment. There are also links with the devices industries through the pharmaceutical industry and the Association of the British Pharmaceutical Industry (ABPI). It is therefore possible to develop existing strengths in the health business sector through collaboration across businesses and organisations in order to share facilities, expertise and best practice. In order to help define the health business sector in Wales, SIC codes can be used to classify health sector firms (TABLE 1).

TABLE 1: Health sector firms SIC codes

\begin{tabular}{|l|l|l|}
\hline Listing number & Health sector & SIC code \\
\hline 1. & Biotechnology firms & 7310 \\
\hline 2. & Pharmaceutical firms & 2441,2442 \\
\hline 3. & Medical equipment firms & 3310 \\
\hline 4. & Health product firms & 2441,2442 \\
\hline $5 . *$ & Alternative health product firms & 2570,6410 \\
\hline $6 . *$ & Other health firms & 3443,4130 \\
\hline
\end{tabular}

$5 .^{*} \& 6 .{ }^{*}$ alternative health and other health products

To provide a comprehensive coverage of health sector companies, the following alternative cures, products and health foods are included.

5. Homeopathic preparations (manufacture)

6. Hearing aid (electronic) manufacture

6. Baby foods (manufacture)

6. Baby foods (milk based) manufacture

Health sector firms can be categorised according to a classification for health R\&D performers as follows:

1. Biotechnology firms

2. Pharmaceutical firms

3. Medical equipment firms (including instrumentation and diagnostic equipment)

4. Health product firms

5. Alternative health product firms

6. Other health firms 
For the definition of "R\&D" in the health context, the definitions of R\&D and health research R\&D used by the OECD have been adopted for this study (OECD, 1994):

"Research and experimental development comprise creative work undertaken on a systematic basis in order to increase the stock of knowledge, including knowledge of man, culture and society, and the use of this knowledge to devise new applications."

\section{The definition of "R\&D" in the health context is as follows:}

"Health research and development is a process for generating systematic knowledge and for testing hypotheses, within the domain of medical and natural sciences as well as social sciences including economics and behavioural science. The information resulting from this process can be used to improve the health of individuals or groups."

The main categories of the classification of health R\&D (based on the Global Forum for Health Research) have been followed:

1. Non-oriented, fundamental research

2. Health conditions, disease or injuries (classified by disease)

3. Exposure, risk factors that impact on health (determinants)

4. Health systems research

5. Research capacity building

Therefore the "R\&D" definition in the health context is generic and covers a wide range of health activities appropriate to the health sector.

\section{CASE STUDY APPROACH}

For the exploration of the importance of the internal and external R\&D activities of companies in the health sector it was decided to use the case study approach - the results of which are reported in the case studies in this paper. The case study approach involved extensive examination of the phenomenon of research and development in the organisations researched. Indeed, some of the most interesting research to emerge in the twentieth century has been derived from research undertaken within a small number of organisations (Bryman, 1989). Although case study research declined during the 1960s it has experienced an increase in popularity in recent years and now represents a sound methodological paradigm (Yin, 1994).

A case study approach is an example of a phenomenological methodology that has been used as a valid research methodology (Tellis, 1997). It is important to understand for case study research that the context of the research is of paramount importance. Data for the case studies has been obtained from information relating to the organisations investigated. These have been combined with secondary and internal data sources from the organisations for completeness. The case studies offer a methodology through observation, reconstruction and analysis that provides a thorough investigation to the research (Tellis, 1997). It is also argued by Aaker et al (1998) that case studies are often a logical method of analysis in a complex situation. However, case study research has often been criticised since it is claimed that it is designed incorrectly. In fact, this view arises from the opinion that the case study research structure has traditionally been loose and emerging in terms of data collection. Three case studies have been undertaken in the health sector and these are reported below according to the company background, research and development activity and the importance of R\&D.

\section{HEALTH SECTOR COMPANY CASE STUDIES}

\section{Therapagent Ltd}

\section{Company background}

Therapagent Ltd designs and predicts selective therapeutic agents in the G Protein-coupled Receptor (GPR) area with special reference to developing alleviating agents in the areas of asthma, cardiovascular disease, incontinence and Alzheimer's disease. The company is a computation based rational drug discovery firm. The objective is to discover better medicines for the treatment of common disease. This is through the fast optimisation of molecules which the company designs to act upon receptors involved with these diseases.

\section{Research and Development activity}

Therapagent's focus for R\&D is G-protein coupled receptors (GPCRs) with considerable therapeutic and economic potential. This is evidenced through more than 50 percent of drugs marketed (more than 25 percent of the leading one hundred best selling drugs) by targeting twenty GPCRs, treat a broad range of diseases. Consequently, the central element of pharmaceutical research is the development of highly selective and specific small molecule ligands that modulate GPCRs. Recently the pharmaceutical industry has given more attention to identification of new potential drug targets. This has been driven by developments in Genomics and Bioinformatics. It is believed that in the short term this will increase drug discovery costs and development. It is Therapagent's approach to concentrate on lead identification and optimisation of targets in areas of unmet clinical need that have some existing level of validation. Here there may be an opportunity, through greater specificity and selectivity than those drugs in development, to produce new drugs. Therapagent's objectives therefore are to discover drugs in terms of efficiency and efficacy that make a significant improvement on what is available in the market.

The scientific expertise of Therapagent Ltd is in its small highly effective team of World class pharmacologists and chemists, computational analysis of protein 3-D structures using state of the art commercially licensed software and rigorous interpretation, through the Davies-Nederkoorn model of the structure and mechanisms of GPCRs, of drugreceptor interactions. These provide a platform to identify and test pharmacologically active modules that interact at receptors in targeted disease pathologies. This enables novel compounds to have accelerated adoption in the pharma pipeline by reducing lead optimisation time.

\section{Conclusions: the importance of R\&D}

The strength of Therapagent Ltd is in its use of extensive past research by scientists in the area of GPCR on drug receptor interactions. This has resulted in the development of a structural mechanism for GPCRs which will challenge, on the basis of mode of action, other models. A precise understanding of the mode of action for use in the design of stimulatory and partially stimulatory molecules has been acquired by Therapagent's scientists. Therapeutic targets are diverse, representing a large population of patients with high level of unmet need. Areas where drugs are under development are for Alzheimer's disease, acute heart attack and urinary incontinence. Business expertise is in the biotechnology and pharmaceutical industries through the members of the board of directors, which reflects the significance of R\&D activity for the business.

\section{Encapsutech Ltd}

Company background

Encapsutech Ltd offers sophisticated controlled release systems to the pharmaceutical industry. Encapsutech is a 
particle engineering company taking to market a novel micro-reactor technology for the development and production of high quality particles for the pharmaceutical, food and cosmetic markets. Encapsutech's unique bio encapsulation technology has applications in a range of therapeutic areas including cell therapies, small molecules and biopharmaceuticals. The company is addressing the limitations of drug delivery through the development of novel controlled release systems. Through integration of expertise in cell biology, polymers and micro fluidics Encapsutech is developing novel micro encapsulation systems and production technologies suitable for a broad range of therapeutic applications. Core technology is being applied for the collaborative development of drug delivery systems for biotechnology and pharmaceutical partners in the areas of vaccines, adjunct therapies, cell therapies, combination products and controlled release of biopharmaceuticals and small molecules.

Since the drug discovery market is becoming increasingly competitive, controlled release and delivery technologies with the aim to achieve sustained and localised delivery of therapeutics in the human body are of considerable importance to the pharmaceutical industry. In fact, controlled delivery has potential to reduce side effects, improve drug effectiveness and increase patient acceptance. Novel controlled release technologies will enable wide applications including clinical development of therapies, generics that can benefit from a new commercial life cycle, new drugs with delivery not developed and patent extension for proprietary drugs.

\section{Research and Development activity}

A breakthrough bio encapsulation technology for controlled delivery and sustained release of therapeutics using microcapsules has been developed in response to limited current drug delivery systems. These can be produced in commercial volumes using GMP compliant micro plants, maintain drug stability, achieve product uniformity and quality and are designed for optimal release rates.

The key advantage of Encapsutech is the suitability of the technology developed for encapsulating therapeutic material and the capability to design, develop and produce polymer microcapsules. These can be produced in commercial volumes using GMP compliant micro plants, are finely loaded with active ingredients (small molecules, biopharmaceuticals and cells) and use a broad range of biocompatible polymers.

The management team includes the chief executive, business development director and technical manager; there is a board of directors involving the chairman, a nonexecutive director, the business development director, chief executive and non-executive director and a scientific advisory board composing three leading experts.

The services provided by the company involve applying the core technology for collaborative development of drug delivery systems for pharmaceutical and biotechnology partners. Through design, development and implementation the company offers its clients the opportunity to develop more efficient micro particle processes. In order to do this Encapsutech uses a unique and wide range of engineering expertise, materials and chemistry through a range of services. These include the identification of regulatory and validation issues to be addressed, scale-up of microcapsule production volumes and rapid microcapsule development using proprietary micro fluidic technology.

With regards to collaborative research agreements from an initial proof of concept engagement Encapsutech works with clients to develop micro particle technology to implement under licence. Concerning partnerships Encapsutech is interested in partnering companies with the aim to co-develop controlled release therapies based upon bio encapsulation technology. Further to this, regarding "in licensing" Encapsutech seeks opportunities to "in-licence" technologies to enable development of novel therapies.

Encapsutech applications involve a smart drug delivery capability to enable a wide range of therapeutic applications including biopharmaceuticals (development of controlled release biopharmaceuticals that confer distinct advantages over existing formulations), small molecules (encapsulation technology enables new and controlled release versus existing small molecule therapies to be developed) and cell therapies (cell based therapies enable localised and sustained drug delivery under the control of the body's natural feedback mechanism and offer the potential for improved treatments for a range of chronic diseases).

\section{Conclusions: the importance of R\&D}

Encapsutech was formally launched with a unique technology for the fully scalable manufacture of micro- and nano particles. Two months later Encapsutech won a technology investment by raising almost $£ 500,000$ with help from large name backers in order to bring their "cutting edge" technology developed to the market place. The company made further progress with their micro fluidic technologies entering their next evolutionary phase with foundations rooted in "lab on a chip" systems. By the end of the year Encapsutech announced the signing of a collaborative research deal with a medical device company focused on the treatment of cardiovascular disease, cancer and benign tumours. Success followed with Encapsutech being included in the final 50 Real Business, most exciting and innovative companies to watch. This was followed with the development of their particulate drug delivery systems through the introduction of a new micro fluidic technology. Three months later Encapsutech developed the World's first commercial micro plant and targeted growing controlled release and cell therapy sectors with microcapsule technology. Finally, Encapsutech appointed a biotech pioneer as a non-executive director, which illustrated the importance the company places on R\&D activities.

\section{Semimedtech Ltd}

\section{Company background}

Semimedtech Ltd has considerable expertise in the area of power devices, including thermal management aspects, and this was crucial to the formation of the company. Semimedtech has been funded as a venture capital company through a large corporation and is chaired by its founder who has established other electronics companies.

The company is using the latest technology in semiconductor light emitting diodes and laser diode devices to develop and manufacture semiconductor based light source systems. Semimedtech has know-how and intellectual property (IP) regarding efficient thermal management techniques enabling heat to be removed for the operation of devices. Optical design technologies are being developed for efficient light coupling from these devices to target application regions.

\section{Research and Development activity}

Semimedtech operates in the four main areas of Smart LED (light engine modules), consumer systems (healthcare devices), industrial systems (nondestructive testing and agri-foods) and medical systems (skin treatment devices). In particular areas the company licenses technology to 
companies who want to utilise IP in products. The IP portfolio reflects investment in R\&D and this comprises more than ten pending patent applications. IP applies to many aspects of LED systems technology and these range from novel optical and thermal management technologies to methods of skin treatment using LEDs. The company is small and agile and has strong design skills and LED compatibility in the infra-red, visible and ultra-violet wavelengths. An overall manufacturing aim is for customers and there is also the ability to licence IP where potential and volume is high.

There are nine company board members including two university professors (one being the Chairman) a vice chairman, chief executive officer, chief technical officer and an observer. The management team includes the operations manager, systems engineering manager, quality manager, chief technical officer, chief executive officer and LED design manager. The principal investors are a corporation, laser company and University Ventures.

The company is committed to quality management and received ISO 9001:2000 accreditation. Additionally, medical device QMC accreditation ISO 13485:2003 was also achieved. Semimedtech is developing semiconductor based light source modules and systems involving optical design techniques, thermal management and semiconductor optoelectronic device fabrication. The company received venture capital (VC) funding and has subsequently built its product development activity, $R \& D$ and management team.

\section{Conclusions: the importance of R\&D}

Principal markets are in the health care and medical sectors and there is an intellectual property base ready to be exploited in other markets. Target markets are the cosmetic and medical sectors and systems are used by medical practitioners and doctors and are being developed for customers. The company is a market leader in the design, development and production of intelligent higher power light emitting diode (LED) light source illumination systems. Product lines combine patent pending thermal management technology with the advantage of LEDs as a light source for HI growth applications. The company forms long term strategic partnerships with main players in the market rather than offering products for sale on the open market. By doing this the company focuses on technology delivery for applications using high power LED technology. Prototypes are made to clients' specific requirements and these are taken to volume manufacture through the global sister company which is the manufacturing partner. The mission statement of the company is "to become a global leader in the design and manufacture of advanced LED technology solutions and systems to the medical, industrial and consumer markets". Semimedtech provides cost effective fully integrated systems of LED array solutions to satisfy the requirements of customers. Products developed by Semimedtech include optoelectronic modules and systems. These have been developed using patent pending LED array and optical thermal management technologies and they are targeted at providing high power solutions at lower cost for a spectrum of markets. World class performance is exhibited by the systems developed which are aimed at the aesthetic and healthcare sectors. The ultimate aim is to make the company profitable concerning R\&D cash, which underpins the importance of R\&D activities.

\section{SUMMARY/DISCUSSION}

Two considerations of major importance to modern governments with regard to the health sector are what will be the policies needed to guide scientific and technological R\&D efforts and how to organise programmes and initiatives. It appears that there is a need for selectivity and concentration of resources into those sectors in Wales such as health, where there is a critical mass of research and resources which have the potential to be developed to a World class level. The current levels of research activity in the sector have the capacity to be developed if the right policy decisions are made. In relation to this potential there are certain $R \& D$ requirements in the sector that need to be provided for.

Highlighted from the literature review, a major policy research question concerning the importance of $R \& D$ activity in health sector small and medium-sized companies in Wales is the extent to which indigenous technology progress is created by local $R \& D$ or by developments globally (Revesz and Boldeman, 2006). Needless to say, the economic impact of R\&D on health sector companies will be of considerable importance. Within the health sector there will be a number of methods used by enterprises to protect the competitive advantage of their new or improved processes and products. A major influence on the commitment to $R \& D$ programmes by firms in the health sector in Wales is to develop intellectual property (IP). Small enterprises in markets will often need patents in order to release new products (Mazzoleni and Nelson, 1998) and this is evidenced through patents being taken out by companies.

There is an argument that small health businesses will receive most of their technology innovations from other larger companies, and with competitive conditions they will have the incentive to adopt exogenous new technologies without government support. Indeed, at a qualitative level there will be the case both pro and ante for R\&D government support and quantitative analysis is required to determine $R \& D$ subsidies at an optimum level (Revesz and Boldeman, 2006). A number of surveys in the literature have considered time delay and it has been found that time constraints have been identified by health companies as an issue that limits R\&D opportunities.

\section{CONCLUSIONS}

\section{Overall conclusions concerning R\&D activity}

Public schemes for R\&D activities can include subsidies for business R\&D, research by public bodies (especially universities) and IP protection. The small and medium sized health companies studied in Wales reported that they undertook R\&D in partnership with other companies, universities and the NHS. R\&D in universities has the important aim to provide postgraduate students with research skills, and related to this public R\&D creates considerable knowledge spillovers to business through "tacit" knowledge, training of researchers and collaborative ventures. For the health companies investigated, the partnerships companies were involved with included academic research papers, Knowledge Transfer Partnerships (KTPs), consultancies and spin outs. The policy research question concerning the importance of R\&D activity for health sector small and medium-sized companies investigated in this study, is to what extent domestic technology progress is influenced by global developments or domestic R\&D. The answer to this appears to be that domestic technology progress is influenced by both global developments and domestic R\&D.

\section{Recommendations regarding the importance of $R \& D$}

From the findings of the study the following recommendations are made: There is a need for selectivity and concentration of resources into those sectors in Wales such as health sector small and medium-sized companies, where there is a critical mass of research and resources 
which have the potential to be developed to a World class level. Small and medium-sized health companies need to take out patents to release new products. Quantitative analysis is required to determine $\mathrm{R} \& \mathrm{D}$ subsidies to small and medium-sized health companies at an optimal level in relation to the case pro and ante for $R \& D$ government support.

\section{Research limitations and future research}

The small number of health companies investigated, has resulted in limited research findings, although the results are of particular interest to policy makers in terms of the commercialisation of health research and development in these types of companies. It is therefore proposed that future research undertaken will carry out case study research into a larger number of small and medium-sized health companies.

\section{REFERENCES}

[1] Aaker, D., Kumar, V. and Day, G. (1998) Marketing Research, $6^{\text {th }}$ edition, John Wiley and Sons, London,

[2] Acs, Z.J., Audretsch, D.B. and Feldman, M.P. (1994) R\&D Spillovers and Innovative Activity, Managerial and Decision Economics, Vol. 15, No. 2, March, pp. 131-138.

[3] Adams, J.D. (1990) Fundamental Stocks of Knowledge and Productivity Growth, Journal of Political Economy, Vol. 98, No. 4, pp. 673-703.

[4] Adams, J.D. (1993) Science R\&D and Invention Potential Recharge: U.S. Evidence, American Economic Review, Vol. 83, No. 2, pp. 458-462.

[5] Allen Consulting (2005) The Economic Impact of Co-operative Research Centres in Australia Delivering benefits for Australia, Report for the Co-operative Research Centres Association.

[6] Arrow, K.J. (1962) Economic Welfare and the Allocation of Resources for Invention, The Rate and Direction of Inventive Activity, Princeton University, National Bureau of Economic Research.

[7] Arundel, A. (2001) The relative effectiveness of patents and secrecy for appropriation, Research Policy, Vol. 30, pp. 611-624.

[8] Audretsch, D.B. and Vivarelli, M. (1996) Firm's Size and R\&D Spillovers: Evidence from Italy, Small Business Economics, Vol. 8, No. 3, June, pp. 249-258.

[9] Bresnahan, T.F. (1986) Measuring the spillovers from technical advance: mainframe computers in financial services, American Economic Review, Vol. 76, No. 4.

[10] Bryman, A. (1989) Research Methods and Organisation Studies, Unwin Hyman, London.

[11] Caballero, R.J. and Jaffe, A.B. (1993) How high are the giants' shoulders: An empirical assessment of knowledge spillovers and creative destruction in a model of economic growth, National Bureau of Economic Research, Working Paper No. 4370, Cambridge, Massachusetts.
[12] Cooksey, D. (2006) A review of UK health research funding, HMSO, Norwich, December, p. 24.

[13] Eaton, J. and Kortum, S. (1996) Trade in ideas: patenting and productivity in the OECD, Journal of International Economics, Vol. 40, pp. 251-278.

[14] Eaton, J. and Kortum, S. (1999) International technology diffusion: theory and evidence, International Economic Review, Vol. 40, No. 3, pp.537-570.

[15] Ernst Young (2003) A Strategy for Bioscience in Wales, Welsh Development Agency, Cardiff.

[16] Griliches, Z. (1957) Hybrid corn: An exploration in the economics of technological change, Econometrica, Vol. 25, No. 4.

[17]Grilliches, Z. (1992) The search for R\&D spillovers, The Scandinavian Journal of Economics, Vol. 94, pp. 29-47.

[18] Jaffe, A. and Tratjenberg, M. (1998) International knowledge flows: evidence form patent citations, NBER Working Paper No. 6507, USA

[19] Jaffe, A.B., Tratjenberg, M. and Henderson, R. (1993) Geographic localisation of knowledge spillovers as evidenced by patent citations, The Quarterly Journal of Economics.

[20] Levin, R., Klevorick, A.K., Nelson, R. and Winter S.G. (1987) Appropriating the Returns from Industrial Research and Development, Brookings Papers on Economic Activity, Vol. 3, Washington D.C.

[21] Mandeville, T.D. (1998) An Information Economics Perspective on Innovation, International Journal of Social Economics, Vol. 25, pp.357-364.

[22] Mandeville, T.D., Lamberton, D.M. and Bishop, E.J. (1982) Economic Effects of the Australian patent system, AGPS, Canberra.

[23] Mansfield, E. (1985) How rapidly does new industrial technology leak out? The Journal of Industrial Economics, Vol. 34, No. 2, December.

[24] Mansfield, E., Rapoport, J. Romeo, A, Wagner, S. and Beardsley, G. (1977) Social and private rates of return from industrial innovations, Quarterly Journal of Economics, Vol. 71, pp. 221-240.

[25] Mansfield, E., Schwartz, M. and Wagner, S. (1981) Imitation Costs and Patents: An Empirical Study, The Economic Journal, Vol. 91.

[26] Mazzoleni, R. and Nelson, R.R. (1998) The benefits and costs of strong patent protection: a contribution to the current debate, Research Policy, 27, pp. 273-284.

[27] McKinsey Report (2005) Clinical Research in the UK: Towards a single system that reliably delivers distinctive quality and rapid access at reasonable costs, McKinsey and Company.

[28] Miller, C.J., Thomas, B. and Roeller, M. (2020) Innovation management processes and sustainable iterative circles: an applied integrative approach, Journal of Work-Applied Management, Vol. 12, No. 1, pp.69-90. 
[29] Miller, C.J., Thomas, B. and Roeller, M. (2020) Innovation management processes and sustainable iterative circles: an applied integrative approach, Journal of Work-Applied Management Vol. 12, No. 1, pp. 69-90.

[30] Mohnen, P. (1996) R\&D externalities and productivity growth, Science, Technology and Innovation, No. 18, pp. 39-66.

[31] Nadiri, M.I. and Theofanis, P.M. (1994) The Effects of Public Infrastructure and R\&D Capital on the Cost Structure and Performance of U.S. Manufacturing Industries, Review of Economics and Statistics, Vol. 76, No. 1, February, pp. 22-37.

[32] Organisation for Economic Co-operation and Development (OECD) (1994) Definitions of research and development (R\&D), OECD Publications, Paris.

[33] Phillips, R. (1997) Innovation and Firm Performance in Australian manufacturing, Industry Commission Staff Research paper, AGPS, Canberra.

[34] Polanyi, M. (1943) Patent Reform, Review of Economic Studies, Vol. 11, No. 1.

[35] Quah, D. (2003) Digital goods and the new economy, in Jones, D.C. (ed.) New Economy Handbook, Elsevier Academic Press, USA, pp. 291323.

[36] Revesz, J. (1999) Trade-Related Aspects of Intellectual Property Rights, Staff Research paper, Productivity Commission, Canberra.

[37] Revesz, J. and Boldeman, L. (2006) The economic impact of ICT R\&D: a literature review and some Australian Estimates, Occasional Economic Paper, Australian Government Department of Communications, Information Technology and the Arts, Commonwealth of Australia, November pp. 1-140.

[38] Schumpeter, J. (1934) The Theory of Economic Development, Harvard University Press, Massachusetts, USA

[39] Schumpeter, J. (1942) Capitalism, Socialism and Democracy, Harper, New York.

[40] Scotchmer, S. (2004) Innovation and Incentives, MIT Press, Cambridge, Massachusetts.

[41] Tellis, W. (1997) Introduction to Case Study Research, The Qualitative Report, Vol. 3, No. 2.
[42] Thomas, B., Miller, C. and Packham, G. (2007) Assessing R\&D in Wales focussing on WAG's ScienPolicy priority areas of the Energy and Health sectors, Final Report to the Welsh Assembly Government, Welsh Enterprise Institute, University of Glamorgan.

[43] Thomas, B. (2019) University-Industry Collaboration and Regional Innovation Systems in East Asia: An Overview, International Journal of Research in Business Studies and Management, Vol. 6, No. 2, 01-19.

[44] Thomas, B.C. and Murphy, L.J. (eds.) (2019a) Innovation and Social Capital in Organizational Ecosystems, IGI Global, Hershey.

[45] Thomas, B. and Murphy, L. (2019b) Innovation in Organizational Ecosystems: A Preliminary Investigation, Advances in Management and Innovation Conference, May 2019, Cardiff Metropolitan University, Cardiff.

[46] Thomas, B.C. and Thomas, A.M. (2019) The Business of New Process Diffusion: Management of the Early Float Glass Start-ups, Routledge, London.

[47] Thomas, B. and Murphy, L. (2020) Employee Innovativeness in Organisational Ecosystems: An Initial Study, Open Journal of Human Resource Management, Vol. 3, No. 1, 12-21.

[48] Thomas, B., Murphy, L. and Miller, C. (2020) Commercialising Sustainable Energy Research and Development for Small and Medium-Sized Energy Companies, Sumarianz Journal of Business Management and Marketing, Vol. 3, No. 5, 46-55.

[49] Trajtenberg, M. (1990) Economic Analysis of Product Innovation, The Case of CT Scanners, Harvard Economic Studies, Harvard University Press, Cambridge, Massachusetts.

[50] Welsh Assembly Government (WAG) (2006) $A$ Science Policy for Wales? The Welsh Assembly Government's Strategic Vision for Sciences, Engineering and Technology, November, WAG, Cardiff.

[51] Yin, R.K. (1994) Case Study Research - design and methods, $2^{\text {nd }}$ edition, Sage Publications, London. 